J. Lake Sci. (湖泊科学), 2013, 25(1): 138-146

http: //www. jlakes.org. E-mail : jlakes@niglas.ac.cn

(c) 2013 by Journal of Lake Sciences

\title{
杭州西湖轮虫的群落结构及与水体环境因子的关系
}

\author{
饶利华 ${ }^{1,2}$, 吴芝瑛 ${ }^{1,2}$, 徐 骏 ${ }^{1,2}$, 陈 琳 ${ }^{1}$, 张 巍 ${ }^{1,2}$, 陈 均 ${ }^{1,2}$ \\ $(1:$ 杭州市西湖水域管理处,杭州 310002) \\ (2:杭州西湖风景名胜区环境监测站, 杭州 310008)
}

\begin{abstract}
摘 要: 2007 年 1 月- 2010 年 10 月,对杭州西湖进行调查研究,利用综合营养状态指数对西湖的营养状况进行评价, 通 过种类组成、优势种、多样性指数等指标探讨西湖轮虫的群落结构与水体营养状况之间的关系. 结果表明, 西湖总体处于 中-富营养状态. 调查期间共检出轮虫 29 种, 以角突臂尾轮虫 (Brachionus angularis)、螺形龟甲轮虫 (Keratella cochlearis) 等 最为常见; 总数量处于较低的水平, 多样性水平不高; 各采样点在不同年份表现出不同的季节变化规律. 相关性分析结果 表明,西湖轮虫密度与水温、TLI 指数、总氮、高锰酸盐指数、透明度和 $\mathrm{pH}$ 值的相关性高度显著; Margalef 多样性指数和 Shannon-Wiener 多样性指数与水体环境因子表现出不同的相关性. 研究发现, 西湖轮虫结构不仅与水体的营养状况关系 密切,还受引水过程引起的水动力学的影响,从引水人湖口到出水口存在一个以水动力学过程为主导的生态梯度.
\end{abstract}

关键词: 西湖; 轮虫; 群落结构;营养状况

\section{Relationship between environmental factors of the water and rotifer community structure in West Lake, Hangzhou}

\author{
RAO Lihua ${ }^{1,2}$, WU Zhiying ${ }^{1,2}$, XU Jun ${ }^{1,2}$, CHEN Lin $^{1}$, ZHANG Wei ${ }^{1,2}$ \& CHEN Jun ${ }^{1,2}$ \\ (1: Hangzhou West Lake Administration, Hangzhou 310002, P. R. China) \\ (2: Hangzhou West Lake Environmental Monitoring Station, Hangzhou 310008, P. R. China)
}

Abstract: In the present study we evaluated the trophic status of West Lake on basis of investigations from January of 2007 to October of 2010. According to the data associated with species composition, dominant species, density and diversity of rotifers, the relationships between rotifer community structure and eutrophication were evaluated. The result indicated that the water in West Lake had been in a state of eutrophication. The dominant rotifer species were Brachionus angularis and Keratella cochlearis in all 29 species. The amount and diversity of rotifer species are all low. Structures of rotifer community were different in seasons, years and locations. The correlation analysis showed that rotifer density was significantly correlated with water temperature, status of eutrophication, total nitrogen, $\mathrm{SD}, \mathrm{COD}_{\mathrm{Mn}}$ and $\mathrm{pH}$, respectively. There were significant correlations between Shannon-Wiener diversity index and environmental factors, but only total-nitrogen had obvious correlation with Margalef diversity index. The study showed that there existed an ecological gradient of the community structure of rotifers between intake and outlet, which were influenced by hydrodynamics of water diversion system.

Keywords: West Lake; rotifer; community structure; eutrophication

杭州西湖是世界文化遗产地之一, 现有湖泊水域面积 $6.5 \mathrm{~km}^{2}$, 平均水深 $2.7 \mathrm{~m}$. 关于西湖浮游动物的研 究屡见报道 ${ }^{[1-2]}$. 李共国等 ${ }^{[3]}$ 曾对引水和疏浚工程对西湖轮虫群落结构的影响进行研究, 结果表明引水冲污 对西湖表层的浮游轮虫有明显的稀释作用, 然而随着引水量的急剧下降及疏浚工程激活的底泥营养的增 加, 导致轮虫的密度和生物量增加. 2003 年, 西湖引水工程由原来的直接引钱塘江水改造成在引水线上先进 行水质预处理, 这在很大程度上避免了钱塘江水质对西湖水体生态系统的影响, 也使年引水量保持平稳的 水平.

* 杭州西湖风景名胜区管理委员会项目(2010-007) 资助. 2011-12-16 收稿;2012-04-26 收修改稿. 饶利华, 男, 1982 年生,工程师; E-mail : lihuarao@ 163.com. 
轮虫是淡水浮游动物的重要组成部分之一. 由于轮虫个体较小、发育时间短、周转快, 生产量高以及对 环境反应灵敏,所以它在水生态系统结构、功能和生物生产力中具有重要意义. 掌握轮虫群落结构的变化规 律是了解水域生态系统结构和功能的重要内容之一. 同时轮虫是良好的环境指示生物, 轮虫群落的生态特 性可以作为水质生物评价的依据 ${ }^{[4-6]}$. 轮虫群落结构的变化能够及时反映水体环境状况. 因此, 对轮虫群落 结构及其与水体营养状况关系进行研究具有重要意义. 本文对 2007-2010 年西湖轮虫的群落结构进行研 究, 分析西湖轮虫的群落结构和水体营养状况, 为引水改造工程后西湖富营养化评价提供基础资料和生物 学依据.

\section{1 材料与方法}

\section{1 调查方法}

从 2007 年 1 月到 2010 年 10 月,在 $1 、 4 、 7$ 和 10 月份采样 1 次. 采样和计数的方法: 定性样品用 $25^{\#}$ 筷绢网拖网采集,定量样品于湖面表层 $0.5 \mathrm{~m}$ 处用 $2.5 \mathrm{~L}$ 采样器采集水样 $10 \mathrm{~L}$ (部分点位鉴于密度极 小, 而将采样量定为 $20 \mathrm{~L}$ ), 现场用鲁哥氏液固定, 带回实验室沉淀 $36 \mathrm{~h}$ 后浓缩至 $30 \mathrm{ml}$, 以备镜检. 采 集生物样品的同时采集水化学样品. 轮虫的种类鉴 定参考《中国淡水轮虫志》 ${ }^{[7]}$ 和《淡水生物 图谱》 ${ }^{[8]}$.

温度 $(\mathrm{T}) 、 \mathrm{pH}$ 值在采样现场测定; 透明度 $(\mathrm{SD})$ 采用塞氏盘测定; 总氮 ( TN ) 采用碱性过硫酸钾硝 解紫外分光光度法测定; 铵态氮采用纳氏试剂比色 法测定; 硝态氮采用离子色谱法测定; 总磷 (TP) 采 用钿锑抗分光光度法测定; 高锰酸盐指数 $\left(\mathrm{COD}_{\mathrm{Mn}}\right)$ 采用酸性高锰酸钾法测定; 叶绿素 a ( Chl. a) 采用丙 酮提取分光光度法测定 ${ }^{[9]}$.

\section{2 采样点的设置}

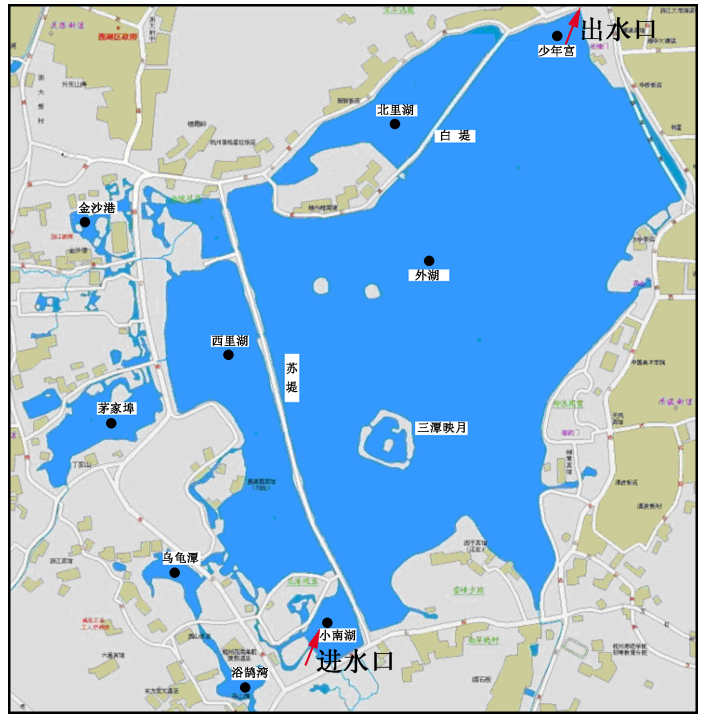

图 1 西湖采样点位示意图

Fig. 1 Location of sampling sites in West Lake

本研究在西湖共设置了 9 个采样点 (图 1). 西湖引水工程的进水口设在小南湖, 出水口设在少年宫, 即 小南湖、外湖和少年宫 3 个点位正好处于引水水流的中轴线上.

\section{3 数据处理}

轮虫的生物多样性采用 Margalef 多样性指数 $(d)$ 和 Shannon-Wiener 多样性指数 $\left(H^{\prime}\right)$, 公式分别为:

$$
d=(S-1) / \ln N, H^{\prime}=-\sum\left(P_{i}\right)\left(\log _{2} P_{i}\right)
$$

式中, $S$ 为种类数, $P_{i}$ 为某种轮虫的密度占总个体密度 (ind. $/ \mathrm{L}$ ) 的比例, $N$ 为轮虫的密度 (ind. $/ \mathrm{L}$ ).

综合营养状态指数计算公式为 ${ }^{[10]}$ :

$$
T L I\left(\sum\right)=\sum W_{j} \cdot T L I(j)
$$

式中, $T L I\left(\sum\right)$ 为综合营养状态指数; $W_{j}$ 为第 $j$ 种参数的营养状态指数的相关权重; $\operatorname{TLI}(j)$ 代表第 $j$ 种参数 的营养状态指数.

几种参数的营养状态指数计算公式为:

$$
\begin{gathered}
T L I(\text { Chl. a })=10(2.5+1.086 \ln \text { Chl. a }) \\
T L I(\mathrm{TP})=10(9.436+1.624 \ln \mathrm{TP}) \\
T L I(\mathrm{TN})=10(5.453+1.694 \ln \mathrm{TN})
\end{gathered}
$$




$$
\begin{gathered}
\operatorname{TLI}(\mathrm{SD})=10(5.118-1.94 \ln \mathrm{SD}) \\
\operatorname{TLI}\left(\mathrm{COD}_{\mathrm{Mn}}\right)=10\left(0.109+2.661 \ln \mathrm{COD}_{\mathrm{Mn}}\right)
\end{gathered}
$$

式中, Chl. a 单位为 $\mathrm{mg} / \mathrm{m}^{3}, \mathrm{SD}$ 单位为 $\mathrm{m}$; 其他指标单位均为 $\mathrm{mg} / \mathrm{L}$.

表 1 中国湖泊 (水库) 部分参数与 Chl. $\mathrm{a}$ 的 相关系数 $r_{i j}$ 及 $r_{i j}^{2}$ 值

Tab. 1 The correlation coefficient $\left(r_{i j}\right)$ between chlorophyll-a and other parameters in Chinese lakes

\begin{tabular}{ccllcl}
\hline 参数 & Chl. a & \multicolumn{1}{c}{$\mathrm{TP}$} & \multicolumn{1}{c}{$\mathrm{TN}$} & $\mathrm{SD}$ & $\mathrm{COD}_{\mathrm{Mn}}$ \\
\hline$r_{i j}$ & 1 & 0.84 & 0.82 & -0.83 & 0.83 \\
$r_{i j}^{2}$ & 1 & 0.7056 & 0.6724 & 0.6889 & 0.6889 \\
\hline
\end{tabular}

$W_{j}$ 的计算以叶绿素 $\mathrm{a}$ 为基准, 其公式为: $W_{j}=r_{i j}{ }^{2} / \sum r_{i j}{ }^{2}, r_{i j}$ 表示第 $j$ 种参数与基准参 数 Chl. $\mathrm{a}$ 的相关系数, $i=1 \sim m$ ( $m$ 为评价参 数的个数). 根据金相灿等的《中国湖泊环 境》 ${ }^{[10]}$, 中国 26 个主要湖泊的 $r_{i j}$ 见表 1 . 本文 亦以此作为参考.

湖泊水体营养状态指数采用 $0 \sim 100$ 的一系列连续数字进行分级, 具体如下:

$T L I\left(\sum\right)<30$ 时为贫营养; $30 \leqslant T L I\left(\sum\right) \leqslant 50$ 时为中营养; $T L I\left(\sum\right)>50$ 时为富营养; $50<T L I\left(\sum\right)$ $\leqslant 60$ 时为轻度富营养; $60<T L I\left(\sum\right) \leqslant 70$ 时为中度富营养; $T L I\left(\sum\right)>70$ 时为重度富营养.

\section{2 结果与分析}

\section{1 西湖营养状况评价}

西湖少年宫、外湖、北里湖等点位 $\mathrm{pH}$ 、总磷、高锰酸盐指数、叶绿素 a 高于其他点位, 标准偏差也相对较 大. 而总氮、硝态氮则是金沙港、茅家埠、乌龟潭、浴鹄湾、小南湖等点位明显高于其他点位 (图 2 ), 这与西湖 湖西水域常年接收氮含量高的钱塘江引水有关. 从综合营养状态指数来看, 西湖总体处于中一富营养状态, 最大值出现在 2009 年 7 月份的少年宫, 为 62.7 (表 2). 从 $T L I$ 年均值来看, 最大值出现在 2010 年的少年宫, 为 55.2 ; 最小值出现在 2007 年的乌龟潭, 为 35.8 .
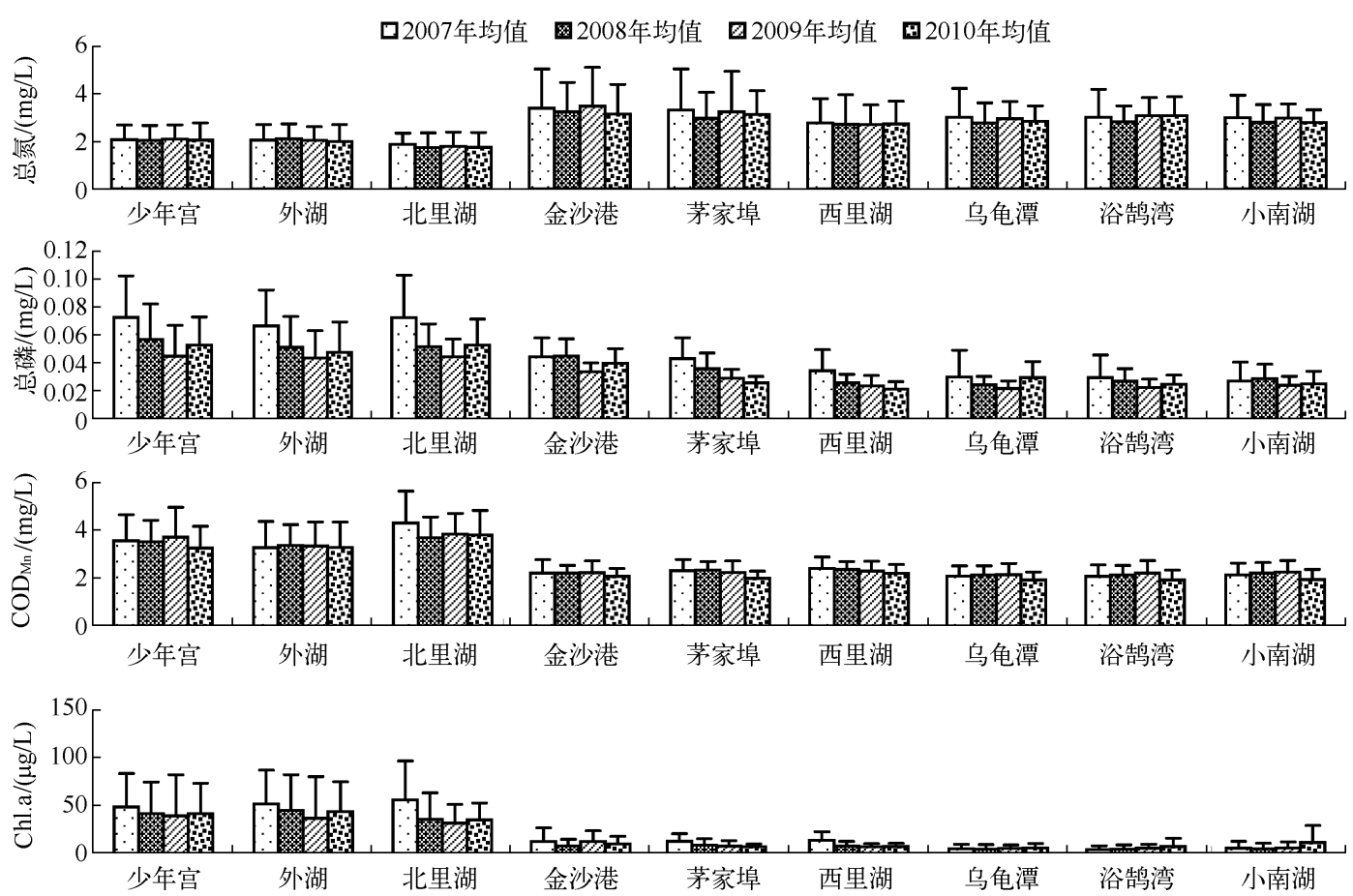

图 2 调查期间西湖各点位的水质特征

Fig. 2 The characteristics of water quality of each sampling site in West Lake during the research 
表 2 西湖各点位综合营养状态指数

Tab. 2 The TLI index of each sampling site in West Lake

\begin{tabular}{|c|c|c|c|c|c|c|c|c|c|}
\hline 年份 & 少年宫 & 外湖 & 北里湖 & 金沙港 & 茅家埠 & 西里湖 & 乌龟潭 & 浴鹄湾 & 小南湖 \\
\hline 2007 年 & $47.7 \pm 6.1$ & $46.6 \pm 5.5$ & $46.8 \pm 3.5$ & $43.3 \pm 2.2$ & $48.1 \pm 1.8$ & $44.3 \pm 2.0$ & $35.8 \pm 1.4$ & $38.8 \pm 2.3$ & $37.8 \pm 3.6$ \\
\hline 2008 年 & $50.7 \pm 7.5$ & $51.8 \pm 7.4$ & $52.1 \pm 5.7$ & $44.4 \pm 3.8$ & $42.9 \pm 2.9$ & $42.2 \pm 2.3$ & $39.4 \pm 2.7$ & $40.0 \pm 2.9$ & $40.2 \pm 3.1$ \\
\hline 2009 年 & $53.4 \pm 6.8$ & $49.8 \pm 4.5$ & $50.8 \pm 2.8$ & $44.2 \pm 2.4$ & $43.8 \pm 2.9$ & $41.3 \pm 2.0$ & $40.3 \pm 1.9$ & $41.2 \pm 3.4$ & $41.2 \pm 5.4$ \\
\hline 2010 年 & $55.2 \pm 5.3$ & $54.8 \pm 5.5$ & $54.1 \pm 4.3$ & $46.4 \pm 0.7$ & $46.1 \pm 1.1$ & $43.3 \pm 1.7$ & $43.3 \pm 4.2$ & $42.6 \pm 5.9$ & $43.0 \pm 7.5$ \\
\hline
\end{tabular}

\section{2 西湖轮虫的群落结构}

2.2.1 种类组成 调查期间共检到轮虫 29 种, 常见种有针簇多肢轮虫、迈氏三肢轮虫、颌花臂尾轮虫、角突 臂尾轮虫、裂足臂尾轮虫、螺形龟甲轮虫、前节晶囊轮虫等. 调查期间, 角突臂尾轮虫和螺形龟甲轮虫在所有 采样点位均出现, 是西湖最常见的 2 个种. 从调查结果来看, 西湖轮虫优势种为针簇多肢轮虫、募花臂尾轮 虫、角突臂尾轮虫和螺形龟甲轮虫等(表 3 ).

表 3 西湖轮虫的种类组成

Tab. 3 Species composition of rotifers in West Lake

\begin{tabular}{|c|c|c|c|c|c|c|c|c|c|}
\hline 种类 & 少年宫 & 外湖 & 北里湖 & 金沙港 & 茅家埠 & 西里湖 & 乌龟潭 & 浴鹄湾 & 小南湖 \\
\hline 迈氏三肢轮虫 (Filinia maior) & ++-+ & ++++ & +++ & +-++ & +++ & +++ & ++-+ & ++-+ & +++ \\
\hline 长三肢轮虫 (Filinia longiseta) & -++- & -+-- & -+-- & ---- & -+-- & -+-- & -+-- & --+- & -+-- \\
\hline 前节晶囊轮虫 (Asplanchna priodonta) & ++++ & +++- & -+++ & -+++ & -+++ & -+++ & -+-- & ++-- & +++- \\
\hline 晶囊轮虫 (Asplanchna sp.) & ---- & ---- & -+-+ & +--- & ---- & ---- & ---- & ---- & ---- \\
\hline 梳状疮毛轮虫 (Synchaeta pectinata) & -+++ & -+++ & -+++ & -+++ & -+++ & -+++ & -+++ & +++ & -++- \\
\hline 疮毛轮虫 (Synchaeta sp.) & -+-- & -+-- & ---- & -+-- & ---- & -+-- & ---- & +--- & ---- \\
\hline 针簇多肢轮虫 (Polyarthra trigla) & ++++ & ++++ & ++++ & ++++ & ++++ & ++++ & -+++ & ++++ & ++++ \\
\hline 䓵花臂尾轮虫 (Brachionus calyciflorus) & ++++ & ++++ & +++ & +-+- & +++- & --++ & +-++ & ++-+ & +++- \\
\hline 角突臂尾轮虫 (B. angularis) & ++++ & ++++ & ++++ & +++ & +++ & +++ & +++ & +++ & ++++ \\
\hline 剪形臂尾轮虫 ( $B$. forficula) & +++- & -+-+ & ++++ & ---- & ---- & --+- & ---- & --++ & -+++ \\
\hline 壸状臂尾轮虫 (B. urceolaris) & ---- & --+- & ---- & ---- & ---- & ---- & ---- & ---- & ---- \\
\hline 镰状臂尾轮虫 (B. falcatus) & ---- & ---- & ---- & ---- & ---- & ---- & ---- & -+-- & ++-- \\
\hline 裂足臂尾轮虫 (B. diversicornis) & ++++ & ++++ & ++++ & ++++ & +++ & +++ & ++-+ & +--+ & ++++ \\
\hline 可变臂尾轮虫 (B. variabilis) & ---- & ---- & ++-- & ---- & ---- & ---- & ---- & ---- & ---- \\
\hline 曲腿龟甲轮虫 (Keratella valga) & -+++ & ++++ & -+++ & ---- & ++-+ & -+-+ & -++- & +++- & +++ \\
\hline 矩形龟甲轮虫 (K. quadrata) & -+++ & -++- & ++-+ & -++- & -+++ & -+-- & -+++ & -+-- & -+-- \\
\hline 螺形龟甲轮虫 (K. cochlearis) & ++++ & ++++ & ++++ & ++++ & ++++ & ++++ & ++++ & ++++ & ++++ \\
\hline 缘板龟甲轮虫 (K. ticinensis) & -+++ & -+++ & -+++ & -+++ & -++- & -+++ & ++++ & -+++ & -+-- \\
\hline 刺盖异尾轮虫 ( Trichocerca capucina) & ++++ & +-++ & +--+ & +-++ & +++ & ++++ & --++ & ++++ & ++++ \\
\hline 同尾轮虫 (Diurella sp. ) & +--- & ---- & ---- & ---- & ---- & ---- & ---- & ---- & ---- \\
\hline 方块鬼轮虫 ( Trichotria tetractis) & ---- & ---- & ---- & +--- & ---- & ---- & ---- & ---- & ---- \\
\hline 单趾轮虫 (Monostyla sp.) & ---- & --+- & --+- & --+- & +++- & --+- & ---+ & +-+- & --+- \\
\hline 月形腔轮虫 (Lecane luna) & ---- & ---- & -+-- & ---+ & +-+- & ---- & --+- & -+-- & -+-- \\
\hline 蹄形腔轮虫 (L. ungulata) & ---- & ---- & ---- & ---- & ---- & ---- & ---- & -+-- & ---- \\
\hline 大肚须足轮虫 (Euchlanis dilatata) & ---- & ---- & ---- & ---- & ---- & ---- & ---- & ---- & -+-- \\
\hline 狭甲轮虫 ( Colurella sp. ) & ---- & ---- & ---- & ---- & ---- & ---- & ---- & --+- & ---- \\
\hline 卵形鞍甲轮虫 (Lepadella ovalis) & ---- & ---- & ---- & ---- & ---- & ---- & --+- & ---- & ---- \\
\hline 鞍甲轮虫 (Lepadella sp. ) & ---- & ---- & ---- & ---- & ---- & ---- & ---- & --+- & ---- \\
\hline 奇异六腕轮虫 (Hexarthra mira) & ---- & ---+ & --+- & --+- & --+- & --+- & --+- & ---- & --+- \\
\hline
\end{tabular}

+ 表示有检出, - 表示未检出; 四个符号自左至右分别表示 $2007 、 2008 、 2009 、 2010$ 年的检测结果. 
2.2.2 数量变化 西湖轮虫的数量整体处于较低的水平. 按每季度每点位采样一次作为一个频次, 四年调查 期间, 总采样频次约为 108 . 而轮虫总密度超过 500 ind. / L 的为 15 频次, 占总采样频次的 $13.9 \%$; 轮虫总密 度超过 $1000 \mathrm{ind}$. / L 的为 5 频次, 占总采样频次的 $4.6 \%$; 轮虫总密度不超过 $10 \mathrm{ind}$. / L 的为 8 频次, 占总采 样频次的 7. 4\% . 调查期间, 西湖轮虫密度最大值为 $2247 \mathrm{ind}$. / L , 出现在 2009 年秋季的少年宫, 优势种为螺 形龟甲轮虫 (1599 ind. /L) 和针簇多肢轮虫 (519 ind. /L) ; 而 2008 年秋季和冬季的小南湖, $20 \mathrm{~L}$ 水样经浓缩 后几乎镜检不到轮虫.

从季节变化来看, 各采样点在不同年份表现出不同的变化规律. 以北里湖为例, 2008 年最高密度出现在 春季, 为 $969 \mathrm{ind} . / \mathrm{L}$, 最低密度出现在冬季, 为 $40.5 \mathrm{ind} . / \mathrm{L} ; 2009$ 年最高密度出现在秋季, 为 $1728 \mathrm{ind} . / \mathrm{L}$, 最 低密度出现在冬季, 为 $42 \mathrm{ind}$. $/ \mathrm{L}$; 而到了 2010 年最高密度又出现在夏季, 为 $1273.5 \mathrm{ind}$. / L ( 图 3 ). 相关性分 析结果表明, 西湖轮虫密度不仅与水温的相关性 $(r=0.274, P<0.01)$ 高度显著, 而且与 $T L I$ 指数、总氮、高

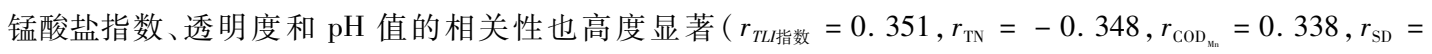
$\left.-0.442, r_{\mathrm{pH}}=0.318 ; P<0.01\right)$. 说明西湖轮虫密度的季节变化不仅与水温、饵料等季节因素有关, 还与受西 湖引水影响较大的总氮、高锰酸盐指数、透明度等其他因素有关. 轮虫群落结构年度季节动态规律变化不 一,反映了西湖整体生态环境受引水等外部环境影响较大,生态系统还比较脆弱.

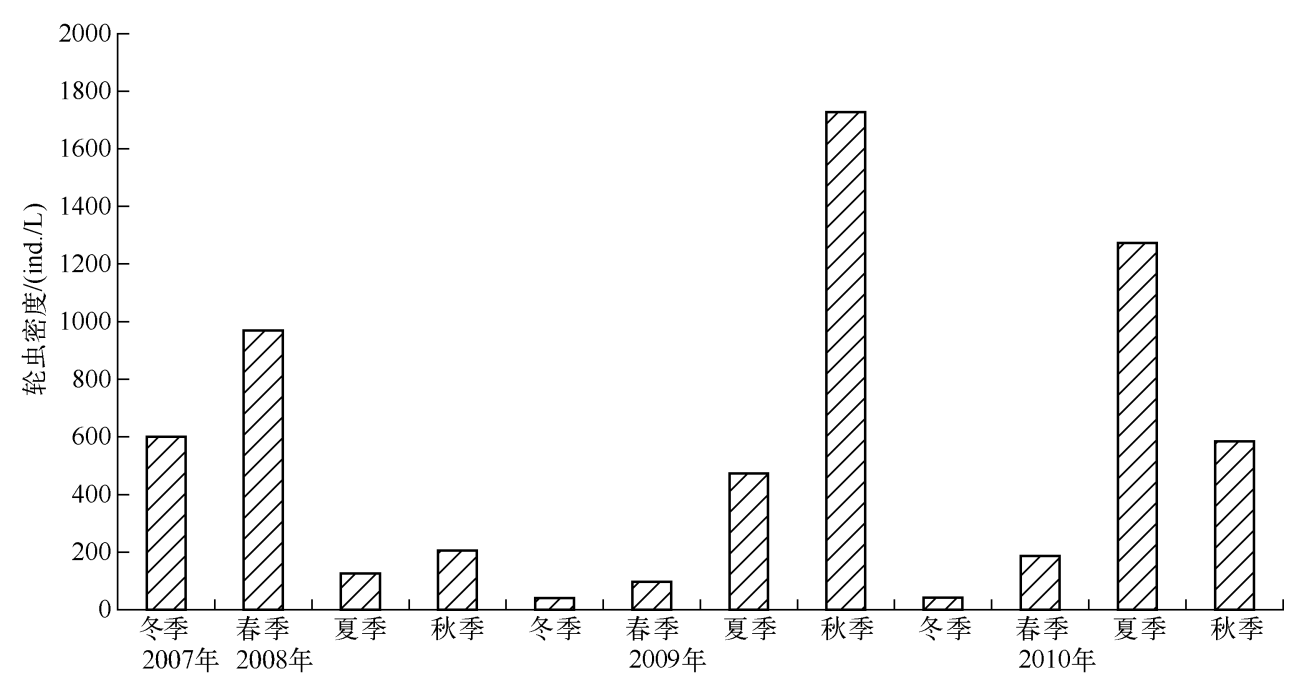

图 3 调查期间北里湖轮虫密度的季节分布

Fig. 3 The seasonal distribution of rotifer density of North West Lake during the research

2.2.3 多样性指数 西湖轮虫的 Margalef 多样性指数年均值最大为 2.16 , 最小为 0.81 ; Shannon-Wiener 多样 性指数年均值最大为 2.45 , 最小为 1.27. 不同点位 Margalef 多样性指数和 Shannon-Wiener 多样性指数存在 差异 (图 4). Margalef 多样性指数和 Shannon-Wiener 多样性指数与 $T L I$ 指数及其他水质指标表现出不同的相 关性. Margalef 多样性指数只与总氮有显著的相关性 $(r=-0.225, P<0.05)$, 而与水温、透明度、总磷、高锰 酸盐指数、Chl. a $、 \mathrm{pH}$ 及 $T L I$ 指数的相关性不显著; Shannon-Wiener 多样性指数与总磷、高镇酸盐指数相关性 显著 $\left(r_{\mathrm{TP}}=0.212, r_{\mathrm{COD}_{\mathrm{H}}}=0.237 ; P<0.05\right)$, 与水温、透明度、Chl. a 、 $\mathrm{pH}$ 及 $T L I$ 指数的相关性高度显著 $\left(r_{\mathrm{T}}=\right.$ $\left.0.386, r_{\mathrm{SD}}=-0.304, r_{\mathrm{Chla}}=0.387, r_{\mathrm{pH}}=0.373, r_{\text {TL指数 }}=0.338 ; P<0.01\right)$.

2.2 .4 水体环境因子与轮虫群落结构的关系轮虫密度与温度、高锰酸盐指数以及 $\mathrm{pH}$ 值呈极显著的正相 关关系; 与透明度、总氮呈极显著的负相关关系; 与总磷、叶绿素 $\mathrm{a}$ 相关性不显著. 轮虫种类数与温度、高 锰酸盐指数、总磷、叶绿素 $\mathrm{a} 、 \mathrm{pH}$ 值均呈显著的正相关关系; 与透明度、总氮呈极显著的负相关关系 (表4). 

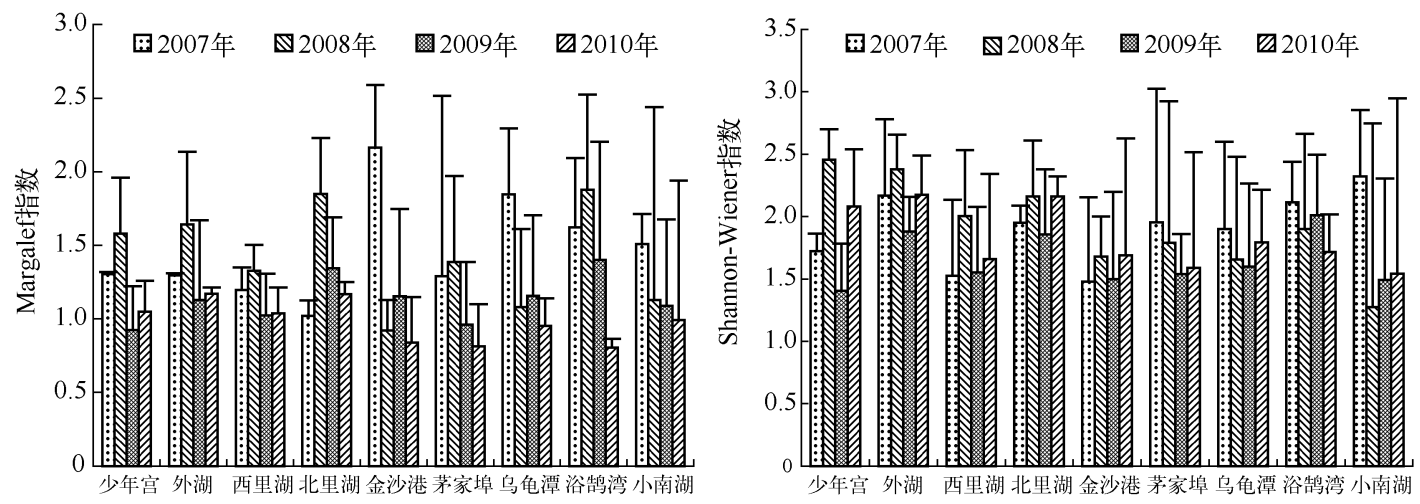

图 4 西湖轮虫的物种多样性指数

Fig. 4 Shannon-Wiener diversity index and Margalef diversity index of rotifer community in West Lake

表 4 水体环境因子与轮虫群落结构指标的相关性分析结果

Tab. 4 The results of correlation analysis between environmental factors of the water and index of rotifer community structure

\begin{tabular}{|c|c|c|c|c|c|c|c|c|c|c|c|c|c|}
\hline & & 轮虫密度 & 种类数 & $d$ & $H^{\prime}$ & $T L I$ 指数 & 温度 & 透明度 & 总氮 & 总磷 & 叶绿素 a & $\mathrm{COD}_{\mathrm{Mn}}$ & $\mathrm{pH}$ \\
\hline \multirow[t]{2}{*}{ 轮虫密度 } & $r$ & 1 & $0.376^{* * *}$ & -0.083 & 0.023 & 0.351 ** & $0.274 * *$ & $-0.442 * *$ & -0.348 ** & 0.173 & 0.153 & $0.338^{* *}$ & $0.318 * *$ \\
\hline & $P$ & & 0.000 & 0.391 & 0.813 & 0.000 & 0.004 & 0.000 & 0.000 & 0.073 & 0.113 & 0.000 & 0.001 \\
\hline \multirow[t]{2}{*}{ 种类数 } & $r$ & $0.376^{* *}$ & 1 & 0.689 ** & $* 0.700$ ** & $0.327 * *$ & 0.383 ** & $-0.384 * *$ & $-0.415^{* *}$ & 0.191 * & 0.269 ** & $0.325^{* *}$ & $0.312 * *$ \\
\hline & $P$ & 0.000 & & 0.000 & 0.000 & 0.001 & 0.000 & 0.000 & 0.000 & 0.047 & 0.005 & 0.001 & 0.001 \\
\hline \multirow[t]{2}{*}{$d$} & & -0.083 & $0.689^{* * *}$ & 1 & $0.709^{* *}$ & 0.088 & 0.115 & -0.100 & $-0.225^{*}$ & 0.046 & 0.137 & 0.105 & 0.115 \\
\hline & $P$ & 0.391 & 0.000 & & 0.000 & 0.364 & 0.236 & 0.304 & 0.019 & 0.639 & 0.157 & 0.278 & 0.235 \\
\hline \multirow[t]{2}{*}{$H^{\prime}$} & $r$ & 0.023 & $0.700^{* *}$ & $0.709^{* *}$ & $* 1$ & $0.338^{* *}$ & $0.386^{* *}$ & $-0.304^{* *}$ & $-0.285^{* *}$ & $0.212 *$ & $0.387^{* *}$ & $0.237^{*}$ & $0.373^{* *}$ \\
\hline & $P$ & 0.813 & 0.000 & 0.000 & & 0.000 & 0.000 & 0.001 & 0.003 & 0.028 & 0.000 & 0.013 & 0.000 \\
\hline \multirow[t]{2}{*}{$T L I$ 指数 } & $r$ & $0.351^{* *}$ & $0.327^{* *}$ & 0.088 & 0.338 ** & 1 & 0.400 ** & $-0.855^{* *}$ & $-0.474 * *$ & 0.808 ** & $0.839 * *$ & $0.768 * *$ & $0.686 * *$ \\
\hline & $P$ & 0.000 & 0.001 & 0.364 & 0.000 & & 0.000 & 0.000 & 0.000 & 0.000 & 0.000 & 0.000 & 0.000 \\
\hline \multirow[t]{2}{*}{ 温度 } & $r$ & $0.274^{* *}$ & $0.383^{* *}$ & 0.115 & $0.386^{* *}$ & $0.400 * *$ & 1 & $-0.329 * *$ & $-0.424^{* *}$ & 0.293 ** & 0.427 ** & $0.256^{* *}$ & $0.394 * *$ \\
\hline & $P$ & 0.004 & 0.000 & 0.236 & 0.000 & 0.000 & & 0.001 & 0.000 & 0.002 & 0.000 & 0.007 & 0.000 \\
\hline \multirow[t]{2}{*}{ 透明度 } & & $-0.442 * *$ & $-0.384 * *$ & -0.100 & $-0.304 * *$ & $-0.855 * *$ & $-0.329 * *$ & 1 & $0.596^{* * *}$ & $-0.676 * *$ & -0.660 ** & $-0.652 * *$ & $-0.622 * *$ \\
\hline & $P$ & 0.000 & 0.000 & 0.304 & 0.001 & 0.000 & 0.001 & & 0.000 & 0.000 & 0.000 & 0.000 & 0.000 \\
\hline \multirow[t]{2}{*}{ 总氮 } & & $-0.348 * *$ & $-0.415^{* *}$ & $-0.225^{*}$ & $-0.285^{* *}$ & $-0.474 * *$ & $-0.424^{* *}$ & $0.596^{* *}$ & 1 & $-0.384 * *$ & -0.515 ** & $-0.539 * *$ & -0.536 ** \\
\hline & $P$ & 0.000 & 0.000 & 0.019 & 0.003 & 0.000 & 0.000 & 0.000 & & 0.000 & 0.000 & 0.000 & 0.000 \\
\hline \multirow[t]{2}{*}{ 总磷 } & $r$ & 0.173 & 0.191 * & 0.046 & $0.212 *$ & 0.808 ** & 0.293 ** & $-0.676^{* *}$ & $-0.384 * *$ & 1 & $0.678 * *$ & $0.711^{* *}$ & 0.561 ** \\
\hline & $P$ & 0.073 & 0.047 & 0.639 & 0.028 & 0.000 & 0.002 & 0.000 & 0.000 & & 0.000 & 0.000 & 0.000 \\
\hline \multirow[t]{2}{*}{ 叶绿素 a } & $r$ & 0.153 & $0.269^{* *}$ & 0.137 & $0.387^{\text {** }}$ & $0.839^{* *}$ & $0.427^{* *}$ & -0.660 ** & $-0.515^{* *}$ & 0.678 ** & 1 & $0.642 * *$ & 0.807 ** \\
\hline & $P$ & 0.113 & 0.005 & 0.157 & 0.000 & 0.000 & 0.000 & 0.000 & 0.000 & 0.000 & & 0.000 & 0.000 \\
\hline \multirow[t]{2}{*}{$\mathrm{COD}_{\mathrm{Mn}}$} & $r$ & $0.338^{* *}$ & $0.325^{* *}$ & 0.105 & 0.237 * & $0.768 * *$ & $0.256^{* *}$ & $-0.652 * *$ & $-0.539^{* * *}$ & $0.711^{* *}$ & $0.642 * *$ & 1 & $0.551 * *$ \\
\hline & $P$ & 0.000 & 0.001 & 0.278 & 0.013 & 0.000 & 0.007 & 0.000 & 0.000 & 0.000 & 0.000 & & 0.000 \\
\hline \multirow[t]{2}{*}{$\mathrm{pH}$} & $r$ & $0.318^{* *}$ & $0.312^{* *}$ & 0.115 & $0.373^{* *}$ & $0.686^{\text {** }}$ & $0.394 * *$ & $-0.622 * *$ & $-0.536 * *$ & 0.561 ** & $0.807^{* *}$ & $0.551^{* *}$ & 1 \\
\hline & $P$ & 0.001 & 0.001 & 0.235 & 0.000 & 0.000 & 0.000 & 0.000 & 0.000 & 0.000 & 0.000 & 0.000 & \\
\hline
\end{tabular}

$r$ 表示 Pearson 相关性; $P$ 表示显著性 (双侧); $* *$ 表示在 0.01 水平 (双侧)上显著相关; $*$ 表示在 0.05 水平 (双侧)上显著 相关; $n=108$. 


\section{3 讨论}

杭州西湖轮虫群落结构季节变化明显, 但每年的规律却不尽相同. 水温被认为是影响轮虫种类季节变 化最主要的环境因子 ${ }^{[11]}$. Hofmann ${ }^{[12]}$ 认为水温是影响轮虫变化的主要但并非唯一决定性因素. Nagata 等 ${ }^{[13]}$ 认为水温、 $\mathrm{pH}$ 值和溶解氧是影响轮虫现存量、现存种类和密度动态的主要生态因子. 在不同水体中, 任何一 个因素的差异都可能导致现存轮虫群落结构不同, 进而导致研究结果出现差异. 章宗涉等 ${ }^{[14]}$ 对武汉东湖长 期的调查研究表明, 轮虫密度高峰期时水温一般在 $20^{\circ} \mathrm{C}$ 以上, 原因是温度上升, 卵的发育时间缩短, 在丰富 的食物供给条件下, 使种群周转加快, 导致种群密度迅速增加, 从而形成密度高峰. 杭州西湖的轮虫密度与 水温的相关性高度显著 $(r=0.274, P<0.01)$, 但却并不是唯一的决定性因素. 而且, 在几个相关性高度显著 的指标中, 水温的相关系数最低 $\left(r_{\mathrm{SD}}>r_{T L}\right.$ 指数 $\left.>r_{\mathrm{TN}}>r_{\mathrm{COD}_{\mathrm{w}}}>r_{\mathrm{pH}}>r_{\mathrm{T}}\right)$. 杭州西湖透明度与轮虫密度显著负相关 $(r=-0.442, P<0.01)$, 这与孔令惠等的研究结果一致 ${ }^{[15]}$. 营养盐在影响浮游植物生产的同时也会对浮游 动物多样性和数量产生一定影响, 但这种影响作用通常是间接的, 浮游动物的种类和数量与营养盐密切相 关 ${ }^{[15]}$. 东湖浮游动物物种多样性与营养水平呈现相反的趋势, 即当水体中营养型向富营养型过渡时物种多 样性降低, 但浮游动物的密度与生物量却增高 ${ }^{[16-17]}$; 太湖三个湖区具有不同的水体营养水平, 同时其轮虫群 落结构也不同 ${ }^{[18]}$. 杭州西湖氮、磷两大主要营养元素与轮虫密度呈现不同的相关性. 轮虫密度与总氮的相关 性高度显著 $(r=-0.348, P<0.01)$, 而与总磷相关性不显著 $(r=0.173, P>0.05)$. 陈立婧等 ${ }^{[19]}$ 对上海崇明 岛明珠湖轮虫群落结构进行研究, 结果表明明珠湖轮虫生物密度与叶绿素 a 含量呈极显著正相关关系. 而 杭州西湖轮虫生物密度与 Chl. a 相关性并不显著 $(r=0.153, P>0.05)$, 这可能与西湖 Chl. a 受引水稀释影 响常年处于较低的水平且水平分布不平衡有关.

多样性指数能定量反映轮虫群落结构中数量、种类组成变化的信息及水体污染程度, 间接反映水体轮 虫群落结构的特点 ${ }^{[20-21]}$. 然而, 多样性指数与水体营养类型之间关系存在不稳定性, 与水质的关系也相当复 杂, 与水体类型、水力学特征、种类鉴定的详细程度等多种因素相关 ${ }^{[22]}$. 谢平等认为营养水平并不是影响物 种多样性的唯一因素, 可能与其他生物和非生物因子的不同有一定关系 ${ }^{[17]}$. 本文通过相关分析发现, Margalef 多样性指数和 Shannon-Wiener 多样性指数与 TLI 指数及其他水质指标表现出不同的相关性. Margalef 多样性指数只与总氮有显著的相关性, 而与水温、透明度、总磷、高锰酸盐指数、Chl. a、 $\mathrm{pH}$ 及 $T L I$ 指数的相关 性不显著; Shannon-Wiener 多样性指数与总磷、高锰酸盐指数相关性显著, 与水温、透明度、Chl. a、 $\mathrm{pH}$ 及 $T L I$ 指数的相关性高度显著. Margalef 多样性指数和 Shannon-Wiener 多样性指数与轮虫密度的相关性不显著 $\left(r_{\text {Margalef }}=-0.083, r_{\text {Shannon-Wiener }}=0.023 ; P>0.05\right)$, 而与种类数之间相关性均高度显著 $\left(r_{\text {Margalef }}=-0.689\right.$, $\left.r_{\text {Shannon-Wiener }}=0.700 ; P<0.01\right)$.

轮虫发育快、周期短, 能迅速地反应环境的变化, 被认为是水质和环境良好的指示生物 ${ }^{[23-26]}$. 一般认为, 随着水体营养水平的上升, 轮虫的种类和数量有逐渐增加的趋势. 相关分析结果表明, 西湖轮虫密度与综合 营养状态指数存在高度显著的相关性 $(r=0.351, P<0.01)$. 然而, 杭州西湖作为城市浅水型湖泊, 多年来一 直施行引水工程, 水力滞留时间相对较短. 因此, 西湖轮虫群落结构及其与水体理化、生物因子的关系和其 他湖泊的研究结果存在一定的差异 ${ }^{[15,27]}$. 小南湖站点 (引水人湖口) 轮虫密度常年处于一个较低的水平, 多 样性水平低, 季节变化不明显; 少年宫站点 (出水口) 多样性水平较高, 季节变化明显. 从引水人湖口到出水 口存在一个由水动力学过程为主导的生态梯度 ${ }^{[15]}$ (图 5). 西湖轮虫密度不仅取决于水温、营养盐含量等因 素, 还受引水过程引起的水动力学的影响.

\section{4 结论}

1) 西湖综合营养状态指数年均值介于 35.8 55.2 之间,西湖总体处于中-富营养状态;

2) 西湖轮虫数量上整体处于较低的水平, 多样性水平不高; 以角突臂尾轮虫、螺形龟甲轮虫最为常见; 各采样点在不同年份表现出不同的季节变化规律;

3) 相关性分析结果表明, 西湖轮虫密度与水温、 $T L I$ 指数、总氮、高锰酸盐指数、透明度和 $\mathrm{pH}$ 值的相关 性高度显著 $(P<0.01)$; 
4) Margalef 多样性指数和 Shannon-Wiener 多样性指数与水体环境因子表现出不同的相关性,前者相关 性不显著(除总氮外), 后者相关性高度显著;

5 ) 西湖轮虫结构受引水过程引起的水动力学的影响, 从引水人湖口到出水口存在一个由水动力学过程 为主导的生态梯度.
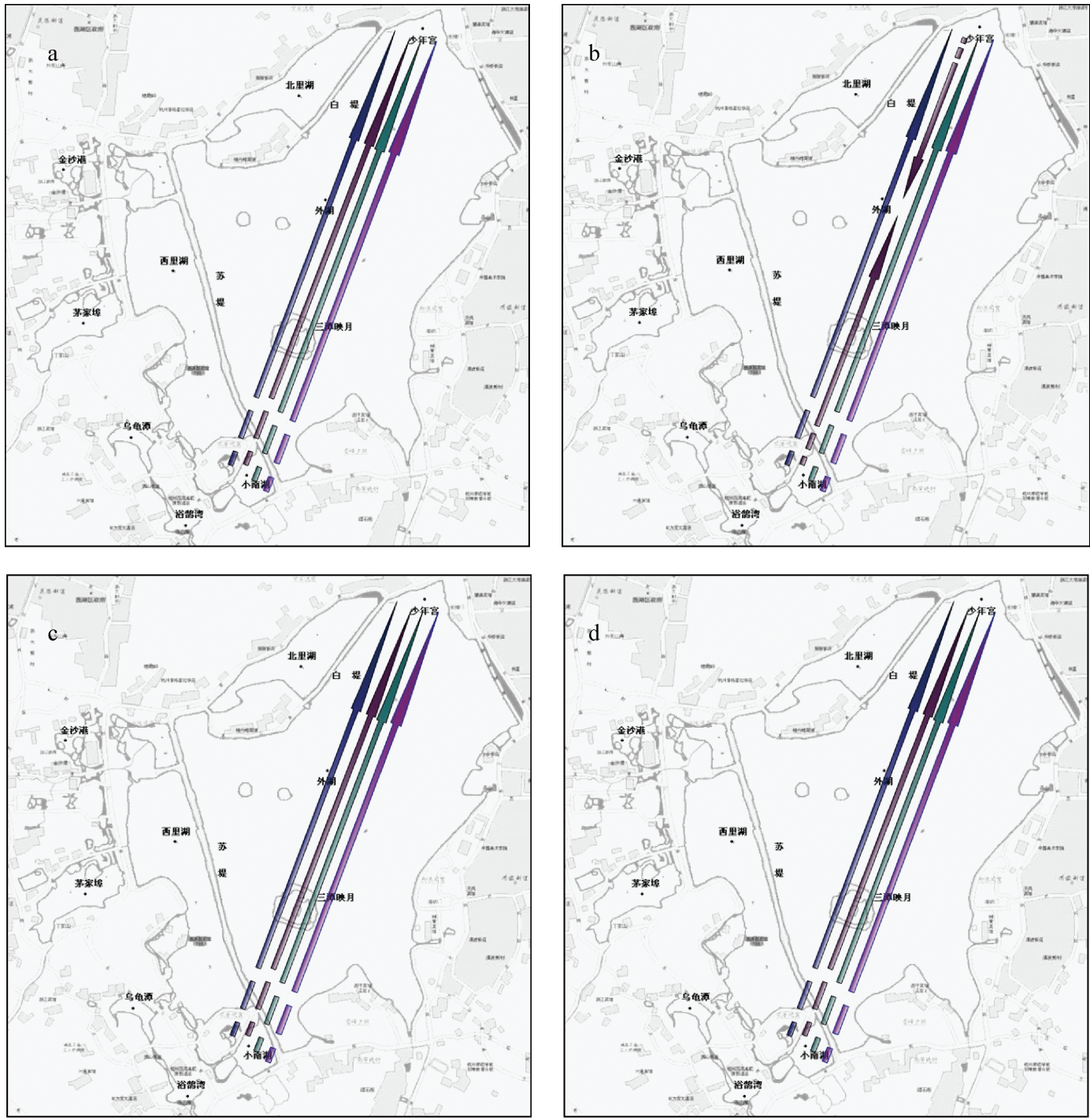

2007年

2008年

2010年 口믐

图 5 西湖引水形成的生态梯度示意图: (a) 引水的流向; (b) TLI 指数随引水水流逐渐增大的梯度变化;

（c）轮虫密度随引水水流逐渐增大的梯度变化; (d) 轮虫种类数随引水水流逐渐增多的梯度变化

( $T L I$ 指数和轮虫密度为年度平均值; 轮虫种类数为周年四次采样镜检所观察到的全部种类;

图 c、图 d 所示并不是表示每次检测结果均符合这种变化)

Fig. 5 The ecological gradient of rotifer caused by waterflow in West Lake: (a) the water flow;

(b) the gradient of TLI index; (c) the gradient of rotifer density; (d) the gradient of rotifer species 


\section{5 参考文献}

[ 1 ] 魏崇德,俞大维. 杭州西湖浮游动物的研究. 杭州大学学报: 自然科学版, 1983,10(增刊):1-17.

[2] 李共国,魏崇德,裴洪平. 引水对杭州西湖轮虫群落结构的影响. 动物学杂志, 1998,33(5):1-4.

[ 3 ] 李共国, 吴芝瑛, 虞左明. 引水和疏浚工程对杭州西湖轮虫群落结构的影响. 水生生物学报, 2007,31(3):386-392.

[ 4 ] Sláde ček V. Rotifeers as indicators of water quality. Hydrobiologia, 1983 ,100:169-201.

[ 5 ] Mäemets A. Rotifers as indicators of lake types in Estonia. Hydrobiologia, 1983,104:357-361.

[6 ] Devetter M. Influence of environmental factors on the rotifer assemblages in an artificial lake. Hydrobiologia, 1998, 387/ $388: 171-178$.

[ 7 ] 王家辑. 中国淡水轮虫志. 北京:科学出版社, 1961:21-283.

[8] 韩茂森,束蕴芳. 淡水生物图谱. 北京: 海洋出版社, 1995 :192-219.

[ 9 ] 《水和废水监测分析方法》编委会. 水和废水监测分析方法:第 4 版. 北京: 中国环境科学出版社,2002.

[10］金相灿,刘树坤,章宗涉.中国湖泊环境. 北京:海洋出版社,1995.

[11] May L. Rotifer occurrance in relation to water temperature in Loch Leven, Scoland. Hydrobiologia, 1983, 104:311-315.

[12] Hofmann W. The influence of abiotic environmental factors on population dynamics in planktonic rotifers. Arch Hydrobiol Beih, 1977, 8: 77-83.

[13 ] Nagata T, Hanazato T. Different predation impacts of two cyclopoid species on a small-sized zooplankton community : an experimental analysis with mesocosms. Hydrobiologia, 2006, 556: 233-242.

[14] 章宗涉,黄祥飞. 淡水浮游生物研究方法. 北京:科学出版社, 1991:232-252.

[15] 孔令惠, 蔡庆华, 徐耀阳等. 丹江口水库浮游轮虫群落季节变动特征及其与环境因子的关系. 湖泊科学, 2010,22 (6) :941-949.

[16] 黄祥飞,陈雪梅,伍悼田等. 武汉东湖浮游动物数量和生物量变动的研究. 水生生物学集刊, 1984,8(3):345-358.

[17] 谢 平, 诸葛燕,戴 䒭等. 水体富营养化对浮游动物群落多样性的影响. 水生生物学报, 1996,20(增刊):30-37.

[18] 杨桂军,潘宏凯,刘正文等. 太湖不同富营养水平湖区轮虫季节变化的比较. 湖泊科学,2007,19(6):652-657.

[19] 陈立婧,顾 静,彭自然等. 上海崇明岛明珠湖轮虫群落结构. 应用生态学报,2009,20(12):3057-3062.

[20] Mäemets A. Rotifers as indicators of lake types in Estonia. Hydrobiologia, 1983,104:357-361.

[21] 黄祥飞,胡春英,伍焯田. 武昌东湖的轮虫. 水生生物学报, 1985,9(2):129-142.

[22] 雷安平,施之新,魏印心. 武汉东湖浮游藻类物种多样性的研究. 水生生物学报, 2003,27(2):179-184.

[23] 杨 柳, 陈绵润, 林秋奇等. 一座热带高产渔业水库枯水期轮虫的群落组成与动态分析. 湖泊科学, 2008,20(6): 780-789.

[24] 周淑婵,黄祥飞,唐 涛等. 香溪河库湾轮虫现状及水质评价初探. 水生生物学报,2006,30(1) :52-57.

[25] 胡菊香,郑金秀,赵先富等. 长江上游轮虫群落纵向演替研究. 水生态学杂志, 2009,2(2):94-100.

[26] 林秋奇,赵帅营,韩博平. 广东省水库轮虫分布特征. 生态学报,2005,25(5):1123-1131.

[27] 郭 凯,赵 文,殷守仁等. 北京官厅水库轮虫群落结构与水体富营养化状况. 湖泊科学,2010,22(2):256-264. 